\title{
Diversifying Initial Teacher Education: Who Utilises Alternative Entry Routes to Teaching \& How They Compare to Direct Entry Students
}

\author{
Katriona O’Sullivan, Gareth Burns, Niamh Bird
}

Department of Adult and Community Education Maynooth University Kildare, Ireland.

\begin{abstract}
Recognition of the growing homogeneity of the Irish teaching body (Keane \& Heinz, 2016), and increasing awareness of the positive impact a more diverse teaching population have on disadvantaged and diverse students' educational engagement, has precipitated an Irish policy response which has included funding a university foundation course (FC) which supports students who are underrepresented in teaching, to progress into initial teacher education (ITE).

There is a dearth of empirical research on who is accessing these interventions, and how these students differ from those who 'usually' apply to and enter ITE directly. Consequently, in September 2018, twenty FC students and eighteen students from the direct entry group completed an on-line survey in order to compare the demographic make of both groups.

The results of the descriptive analysis indicate that students utilising the ITE FC are more diverse in ethnicity, disability status and academic history, and have greater levels of disadvantage in terms of family history of education and family occupation than those entering ITE directly. These results highlight the value of utilising alternative entry routes to ITE, and their potential to support those disadvantaged and underrepresented to take the initial step into ITE.
\end{abstract}

Keywords: Teacher Diversity; ITE Foundation Courses; Access to ITE and Higher Education. 


\section{Introduction}

In recent years Ireland has witnessed unprecedented growth in the number of diverse populations living and working across the country (Smyth, Darmody, McGinnity, \& Byrne, 2009). This has resulted in increasingly complex and diverse school populations. Education policy has responded by attempting to place inclusive practice, and diversity, front and centre, resulting in the introduction of the Diversity in Teacher Education longitudinal programme of research and the Programme for Access to Higher Education (PATH) - both recognising the need for a teaching profession which reflects the diverse student body. Running alongside the challenges that growing diversity brings, is the broader issue of equity of access to higher education (HE), and high-status professions, for students considered disadvantaged. In this context disadvantaged is defined as those individuals whose personal, family, social, and/or economic circumstances have hindered their ability to participate fully in education. Research shows that despite significant investment in education initiatives, disadvantaged students are five times less likely to gain access to university than their more affluent peers (Hannon, Faas \& O’Sullivan, 2018; O’Sullivan, Robson \& Winters, 2018) and access to high-status professions is often stratified by social class. Numerous studies also show that social recruitment to high-status professions, such as law, teaching and medicine, is more unequal than for many other career paths (Crawford, Dearden, Micklewright \&Vignoles, 2017; Keane \& Heinz, 2016) and that a myriad of academic, aspirational and cultural factors often hinder the opportunities of disadvantaged students (O’Sullivan, Bird, Robson \& Winters, In press).

One profession that is particularly difficult to access for cultures and classes is teaching. Recent data shows that over $90 \%$ of Irish pre-service teachers are white, settled, middle-class, females (Keane \& Heinz, 2016). In line with the growing focus on equity of access, Irish policy makers have begun to reflect on the possible negative impact that such a homogenous teaching body can have on the academic and aspirational development of the diverse student body. Policy makers are beginning to examine the impact that teachers who themselves represent diverse cultures, classes and experiences, have on disadvantaged student's education engagement (Burns, 2016; DES 2002; Lynch and Lodge 2004; Moran 2008; Teaching Council 2008, 2011; Conway, Amel \& Gerwien, 2009; Heinz, 2011) AND on their aspirations to move into the teaching profession. Research is also beginning to focus on the specific challenges facing disadvantaged students when accessing high-status professions like teaching, and there has been growth in the number and type of interventions which aim to support disadvantaged and diverse students to progress into the teaching profession across the Irish HE sector.

In 2017 Maynooth University, Ireland, launched the Turn to Teaching Project; a unique three-year programme that aims to support 100 students from educationally disadvantaged backgrounds to move into Initial Teacher Education (ITE). The programme, funded through the Higher Education Authority (HEA) and Maynooth University, aims to address the 
academic, social and personal challenges faced by underrepresented groups within the teaching profession and offers a meaningful pathways into ITE for students from the Irish Traveller community, migrants, mature students, and students coming from schools listed under the Department of Education's Delivering Equality of Opportunity in Schools (DEIS) programme. It offers a one-year, pre-university, foundation course (FC) entitled 'Think about Teaching'. Historically FCs have been used as a way of supporting targeted groups to transition into university study (O’Sullivan, Byrne, Robson \& Winters, 2019). These are intended for those without the formal entry qualifications for their chosen degree and are designed to prepare students for degree level study (O’Sullivan et al., 2018). In Ireland, they have traditionally been delivered in the university context, and they generally target underrepresented student groups. For the socioeconomically disadvantaged learner and/or the mature learner, the supports offered are designed to facilitate the development of social and cultural capital alongside academic skills and subject specific content. They recognize that the challenges facing such groups are complex; supporting peer relationships, academic growth and confidence, preventing students feeling under qualified compared to their peers, and aiming to provide them with access to bridging capital that support transitions and retention within HE (O'Sullivan et al., 2018). A review of these programmes in Ireland demonstrated the effectiveness of the model in supporting students to progress into HE (Murphy, 2009) and evidence found that retention and graduation statistics were in line with those of direct entry students (Share \& Carrol, 2013) even in courses considered 'elite' or 'hard to access' including medicine and law. Maynooth University's 'Think About Teaching' FC is the first programme which aims to prepare students for teaching training, offering a unique opportunity to examine the type of students who access ITE through alternative entry routes.

Theoretical advancement in this area has focused on understanding the barriers facing disadvantaged students when considering high-status professions. Aspiration focused discourse places the onus on the individual, explaining differential rates of participation on the basis of attitudinal factors, implying that non-participation is due to lack of personal expectation (Bruce \& Bridgeland, 2014). Others assert that academic achievement is the primary barrier to participation (Chowdry, Crawford, Dearden, Goodman, \& Vignoles; 2013; Jones \& Thomas, 2005). With large disparities seen between the educational attainment of disadvantaged students and their more affluent counterparts (Coley, 2002; Burgess, Ding, Hargreaves, Van Ryn \& Phelan, 2008; Feinstein, 2003; McKnight, 2015) this approach frames access to high-status professions in terms of human capital; seeing the barriers in terms of an individual skill deficit (Hannon et al., 2017; Thomas, Yorke \& Woodrow, 2003). Both approaches emphasize barriers which exist within the individual, and indicate impoverished levels of personal agency, including reduced freedom to decide and reduced power to act and be effective (Crocker \& Robeyns, 2009; Wilson-Strydom, 2012, 2016). More complex explanations see 'choice' as a result of the interaction between structural and 
individual characteristics. Disadvantaged students often lack experience of an educational structure which is designed and dominated by the ruling classes, which makes progression, retention and belonging in HE difficult (Reay, 2005; Reay, Crozier, and Clayton, 2009; Reay et al., 2008; HEFCE, 2015). When the structural issues are combined with the individual attitudinal and aspirational deficits, disadvantaged students face significant difficulties when attempting to navigate HE (Chowdry et al., 2013; McKendry, Wright, \& Stevenson., 2014; Loveday, 2015) and high-status professions like teaching (Griffin, \& Hu, 2015; Wilkins, \& Burke, 2015). Furthermore, while these barriers are well defined and described, little is known about the people who actually succeed despite facing these barriers, or about those who choose to take what can be considered the 'road least travelled' in the educational and employment context.

In Ireland policy responses to the homogenous nature of the teaching body have included funding the provision of a university run foundation course which supports students who are considered disadvantaged, and underrepresented in teaching, to progress into ITE degree programmes. Yet, despite the voluminous literature pertaining to widening participation issues there is a dearth of empirical research that seeks to understand who is utilising these interventions, and how these students differ from those who 'usually' apply to and enter ITE directly. Thus, the current study seeks to add to the current body of knowledge by establishing the demographic make-up of the student group participating in the first year of the Think about Teaching FC; it aims to establish the family and personal characteristics of these students and to compare these with students who enter ITE directly in the same university. Hence the research asks the questions; who utilises alternative entry routes to teaching degrees and how do they differ from those who enter ITE directly.

\section{Methodology}

A survey design was employed. In September of 2018 an online survey was sent to all 23 students who had been accepted onto Think about Teaching FC for ITE. Students in the primary teaching degree programme in the university were also invited to complete the survey, through the student social media page. Twenty FC students completed the questionnaire. Eighteen students from the direct entry group completed the survey. Demographic information was collected, including information on ethnicity, age, schooling, academic performance, gender, parental education, family structure, and parental occupation. Descriptive analysis was performed on demographic data to establish the demographic profile of each student group, and to compare the students participating in the FC with the direct entry student sample. 


\section{Findings}

The FC student group were more diverse in their demographic make-up than the direct entry students who completed the survey. Table 1 shows that there are more students with disabilities, from ethnic minority backgrounds, and who have progressed from further education and training, than in the direct entry group. Analysis of the demographics of the two student groups also indicated differences in family structure. The data shows a higher proportion of students entering ITE through the FC are from one parent families in comparison to national averages. In Ireland $18 \%$ of all family units are one-parent families (CSO, 2016) while 28\% of students in the FC are from one-parent families (Figure 1). In relation to the direct entry student group, there was also a lower representation of students from one-parent families in comparison to national averages (10\%). Furthermore, $7 \%$ of the FC group were in the care of the State and/or living with a legal guardian, compared to $0 \%$ of the direct entry students.

Table 1: Demographic comparison of the FC and direct entry students.

\begin{tabular}{ccc}
\hline & Think about Teaching & Direct Entry Students \\
\hline Entrants with Disabilities & 4 & 0 \\
Irish Travellers & 1 & 0 \\
Vocational Training & 3 & 0 \\
Route & 3 & 0 \\
Further Education & 2 & 0 \\
Migrant background & & \\
\hline
\end{tabular}




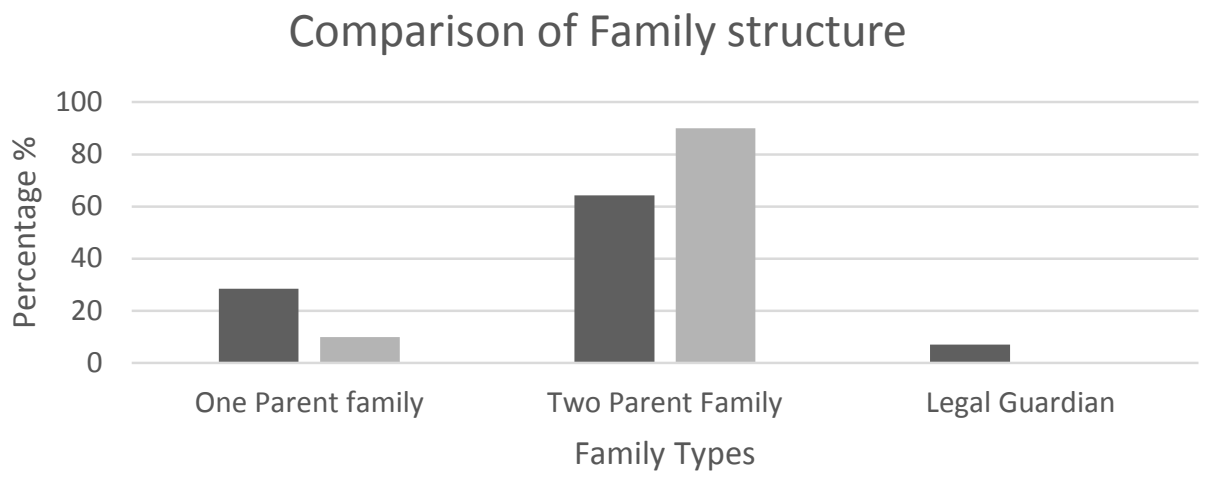

- Foundation Course Direct Entry

Figure 1: Family structure of foundation course students and direct entry primary teaching students

Results also indicate that the FC students' academic achievements in school were significantly lower than that of the direct entry students. In Ireland the Leaving Certificate is a point system, with the maximum being 625 points. Students sit eight subjects in the final two years of school with the highest grades from six of these subjects are tallied to give a score out of 625 . When looking at the average points of the direct entry students we can see that they scored on average 200 points higher than the FC students.

Results indicate that the students utilising the FC had lower levels of cultural capital relating to family history of education, than the direct entry students. Figure 2 shows that students entering ITE directly had a higher proportion of parents who had completed higher and further education compared to the FC students, with $47 \%$ of their fathers having only completed junior certificate or below. When considering the education of the students' mothers, 55\% of the direct entry students' mothers had completed higher or further education, compared to $20 \%$ of the mothers of the FC students. Interestingly $40 \%$ of the mothers of the FC students only completed primary school, showing lowest levels of education experience in the mother of the FC students overall (Figure 2). 


\section{Comparison of Father Education Level}
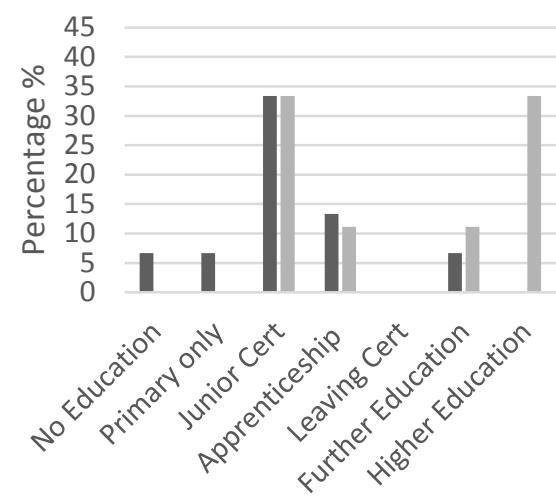

- Father FC Father DE

\section{Comparison of Mother Education Level}
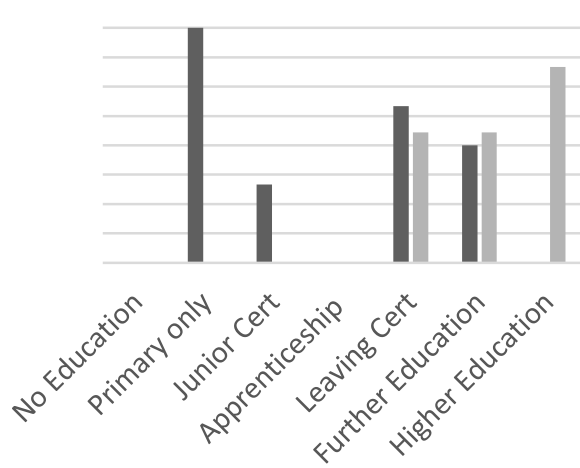

Mother FC Mother DE

Figure 2: Parent education levels of FC students and direct entry primary teaching students

When comparing the FC students with the direct entry students, we see significant differences in father occupations, with FC students' fathers more likely to work in unskilled, skilled and manual professions, while the father of the direct entry students are more likely to work in higher and lower profession (Figure 3). When comparing the FC students with the direct entry students, there is more variation across the mothers' jobs, and while more FC students' mothers work in unskilled, skilled and manual professions, there is also some representation of direct entry students across these occupations. However, more direct entry students' mother work in higher and lower professions than the FC students (Figure 4). 


\section{Comparison of Father Profession}

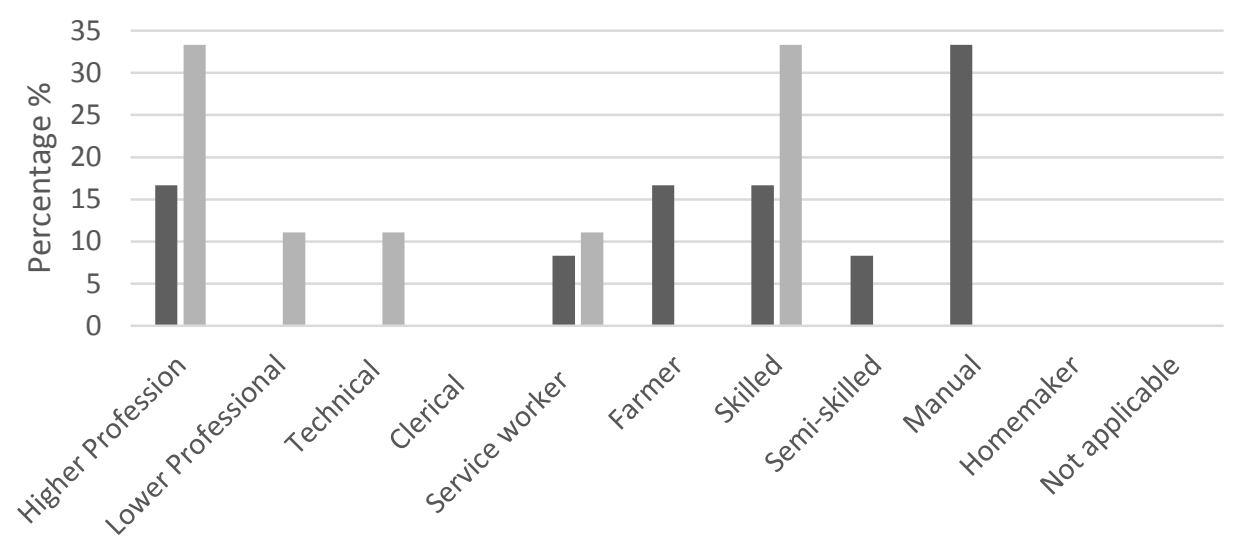

Profession

Father FC Father DE

Figure 3: Occupation of fathers of the FC students and direct entry primary teaching students

\section{Comparison of Mother Profession}

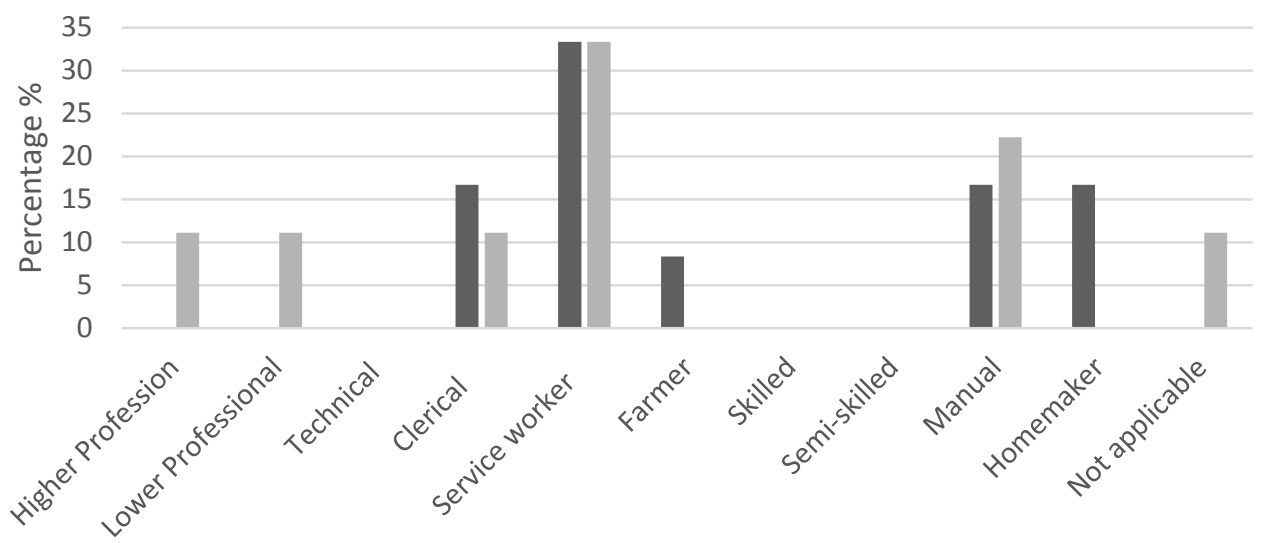

Profession

Mother FC Mother DE

Figure 4: Occupation of the mothers of the FC students and direct entry primary teaching students 


\section{Conclusion}

This research sought to establish the characteristics of students entering ITE through an alternative entry route in Ireland. The results indicate that students utilising the FC are more diverse in ethnicity, disability status and academic history than those entering ITE directly. The FC students are more likely to come from lone- parent families, and have greater levels of disadvantage in terms of family history of education and family occupation, compared to their counterparts who gain entry directly. These results highlight the value of utilising alternative entry routes to ITE, and their potential to support those disadvantaged and underrepresented to take the initial step into ITE. Future research should consider tracking the FC students over the period of the year and into ITE to establish the value these routes offer in terms of diversify ITE.

\section{References}

Burgess, D.J., Ding, Y., Hargreaves, M., Van Ryn, M. and Phelan, S., 2008. The association between perceived discrimination and underutilization of needed medical and mental healthcare in a multi-ethnic community sample. Journal of Health Care for the Poor and Underserved, 19(3), pp.894-911.

Burns, G. (2016). Pedagogies of sameness and care: The daily practices of early career primary teachers in DEIS schools. Irish Teachers' Journal, 4(1) 93-111.

Central Statistics Office (CSO). (2016). Census of Population 2016: Profile 4, Households and Families. https://www.cso.ie/en/releasesandpublications/ep/p-cp4hf/cp4hf/fmls/

Chowdry, H., Crawford, C., Dearden, L., Goodman, A., \& Vignoles, A. (2013). Widening participation in higher education: analysis using linked administrative data. Journal of the Royal Statistical Society: Series A (Statistics in Society), 176(2), 431-457.

Conway, J. M., Amel, E. L., \& Gerwien, D. P. (2009). Teaching and learning in the social context: A meta-analysis of service learning's effects on academic, personal, social, and citizenship outcomes. Teaching of Psychology, 36(4), 233-245.

Griffin, B., \& Hu, W. (2015). The interaction of socio-economic status and gender in widening participation in medicine. Medical education, 49(1), 103-113.

Hannon, C., Faas, D., \& O'Sullivan, K. (2017). Widening the educational capabilities of socio-economically disadvantaged students through a model of social and cultural capital development. British Educational Research Journal, 43(6), 1225-1245.

Heinz, M. (2011). The next generation of teachers: Selection, backgrounds and motivations of second-level student teachers in the Republic of Ireland. PhD, National Univ. of Ireland.

Higher Education Funding Council for England. (2015). "Delivering opportunities for students and maximising their success: evidence for policy and practice 2015-2020." Higher Education Funding Council for England. 
Jones, R. \& Thomas, L. (2005). The 2003 UK Government Higher Education White Paper: A critical assessment of its implications for the access and widening participation agenda. Journal of Educational Policy, 20(5), pp 615-630.

Keane, E., \& Heinz, M. (2016). Excavating an injustice?: nationality/ies, ethnicity/ies and experiences with diversity of initial teacher education applicants and entrants in Ireland in 2014. European Journal of Teacher Education, 39(4), 507-527.

Lynch, K, and A. Lodge. 2004. Diversity in school. Dublin: IPA.

McKnight, A. (2015). Downward mobility, opportunity hoarding and the 'glass floor' London: Social Mobility and Child Poverty Commission.

Murphy, P. (2009). Higher Education Access/Foundation Courses: A Research Report. Higher Education Authority.

O’Sullivan, K., Bird, N., Robson, J., \& Winters, N. (In press). Academic Identity, Confidence and Belonging: the Role of Contextualised Admissions and Foundation Years in Higher Education.

O’Sullivan, K., Byrne, D., Robson, J., \& Winters, N. (2019). Who goes to college via access routes? A comparative study of widening participation admission in selective universities in Ireland and England. Social Inclusion, 7(1), 38-51.

O’Sullivan, K., Robson, J., \& Winters, N. (2018). “I feel like I have a disadvantage”: How socio-economically disadvantaged students make the decision to study at a prestigious university. Studies in Higher Educa- tion. Advanced online publication. https://doi.org/10.1080/03075079.2018.1460591.

Reay, D., Crozier, G. and Clayton, J., 2009. 'Strangers in paradise’? Working-class students in elite universities. Sociology, 43(6), pp.1103-1121.

Share, M. \& Carroll, C. (2013). Ripples of hope: The family and community impact of Trinity College Dublin access graduates. Dublin: Children's Research Centre.

Smyth, E., Darmody, M., McGinnity, F., \& Byrne, D. (2009). Adapting to diversity: Irish schools and newcomer students. Dublin: ESRI.

The Teaching (2011). Policy on the continuum of teacher education. The Teaching Council. 